\title{
The simulation calculation of acoustics energy transfer through the material structure
}

\author{
Peter Zvolenský ${ }^{1}$, Alžbeta Pultznerová ${ }^{2 *}$, and Juraj Grenčík ${ }^{1}$ \\ ${ }^{1}$ University of Žilina, Faculty of Mechanical Engineering, Univerzitná 8215/1, 01026 Žilina, Slovak \\ Republic \\ ${ }^{2}$ University of Žilina, Faculty of Civil Engineering, Univerzitná 8215/1, 01026 Žilina, Slovak \\ Republic
}

\begin{abstract}
The paper deals with the modification of the rail passenger coach floor design aimed at improvement of sound reduction index. Refurbishing was performed by using a new acoustic material with a filamentary microstructure. The materials proposed in research were compared by simulation calculation of acoustic energy transfer trough porous microstructure of filamentary material, and the effect of material porosity on sound reduction index and sound absorption coefficient were observed. This proposed filamentary material can be used in the railway bed structure, too. High degree of noise absorbing, resistance to climate conditions, low specific mass, enable to choose a system of low anti-noise barriers having similar properties as standard high anti-noise walls..
\end{abstract}

\section{Introduction}

The paper deals with simulation calculations of acoustics energy transfer through the structure of porous media. The benefit material composition of sandwich character of structure construction offers a wide range of possibilities application of modern acoustic materials. The aim of research is improving the sound reduction index of rail passenger coach body or improving acoustics parameters of railway track structure. Mineral wool provides good acoustic and thermal insulation properties. As a simple and effective solution to improve the acoustic properties of rail passenger coach body it seems to be utilization of the insulation layer from modern acoustics materials. One of the proposed solutions can be utilization of STERED ${ }^{\circledR}$ material in the railway track structure and also in the structure of a rail passenger coach. From this point of view the paper deals with comparison of acoustic properties of porous materials - mineral wool and STERED® material.

\section{Simulation of acoustics energy transfer through the porous media}

In this case mineral wool and STERED ${ }^{\circledR}$ are porous filamentary materials. The decisive influence on the acoustic properties of porous materials has in particular the porosity (Fig.

* Corresponding author: alzbeta.pultznerova@,fstav.uniza.sk 
1). By using the simulation computation, the effect of the porosity of a filamentary material on the acoustic properties were studied by changing porosity in the range from 5 to $99.5 \%$ by increment of $0.5 \%$ and frequency was changed from $10 \mathrm{~Hz}$ to $10 \mathrm{kHz}$ by increment of $10 \mathrm{~Hz}$. The model presents principle of impedance tube and the inlet signal is defined by following function in complex form. [1]

$$
1 \exp ^{(-i(k x \cdot x+k y \cdot y))} \quad[P a]
$$

$\mathrm{kx}$ - wavenumber axis $\mathrm{x}[\mathrm{rad} / \mathrm{m}]$,

$\mathrm{ky}$ - wavenumber axis y $[\mathrm{rad} / \mathrm{m}]$,

$\mathrm{x}$ - position vector axis $\mathrm{x}[\mathrm{m}]$,

$\mathrm{y}-$ position vector axis $\mathrm{y}[\mathrm{m}]$.

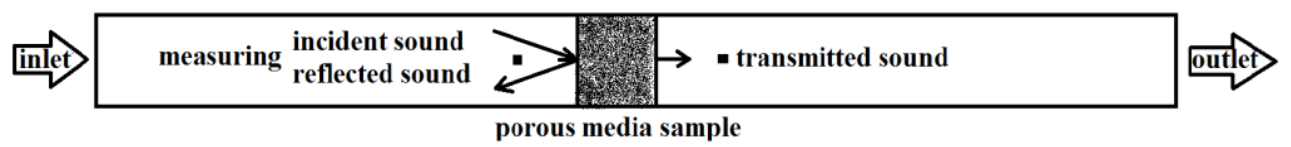

Fig. 1. Model of simulation computation transfer acoustics energy through the porous media [own research].

The results of simulation can be seen in a 3D graph (Fig. 2). The graph was created in MATLAB.

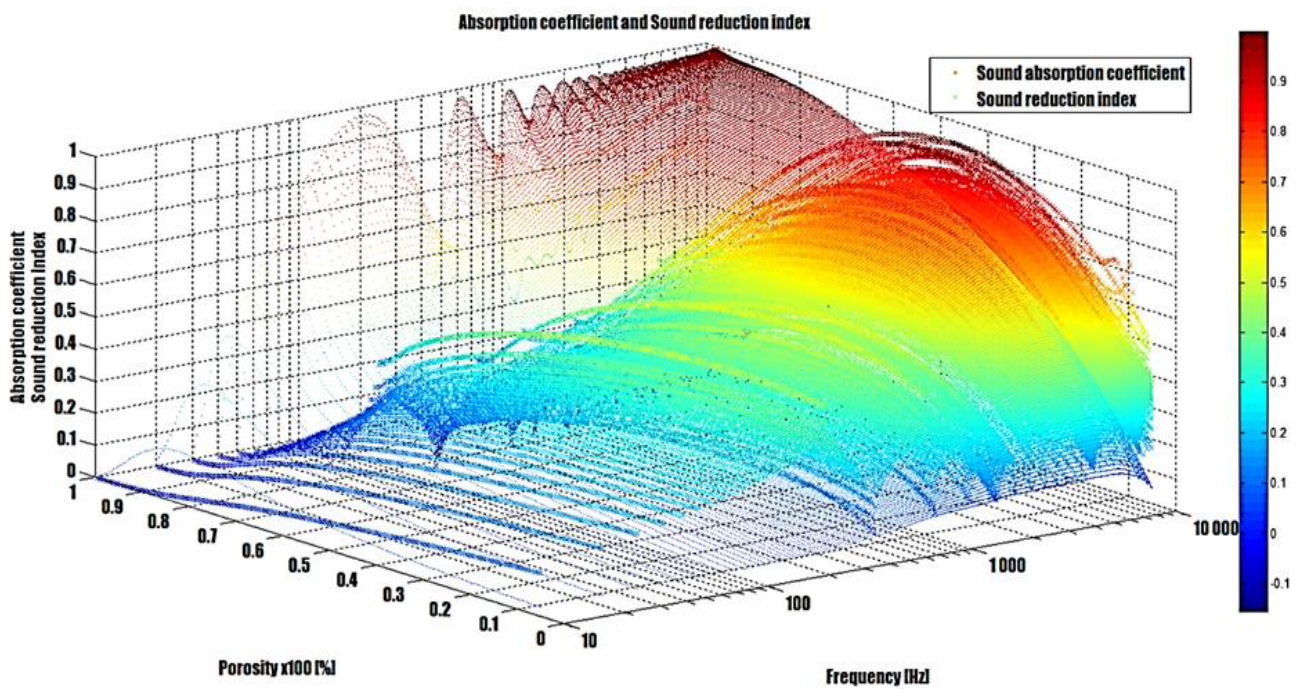

Fig. 2. Frequency dependence of sound absorption coefficient and sound reduction index on the material porosity [own research].

The effect of material porosity on sound reduction index and sound absorption coefficient is better observable on the graph (Fig. 3), which was created by separated specific frequencies. As an example the monitored characteristics of acoustic parameters in frequency $1 \mathrm{kHz}$ are given. The studied relationships are based on energy balance transfer of acoustic energy through the porous microstructure of filamentary material (Fig. 4). 


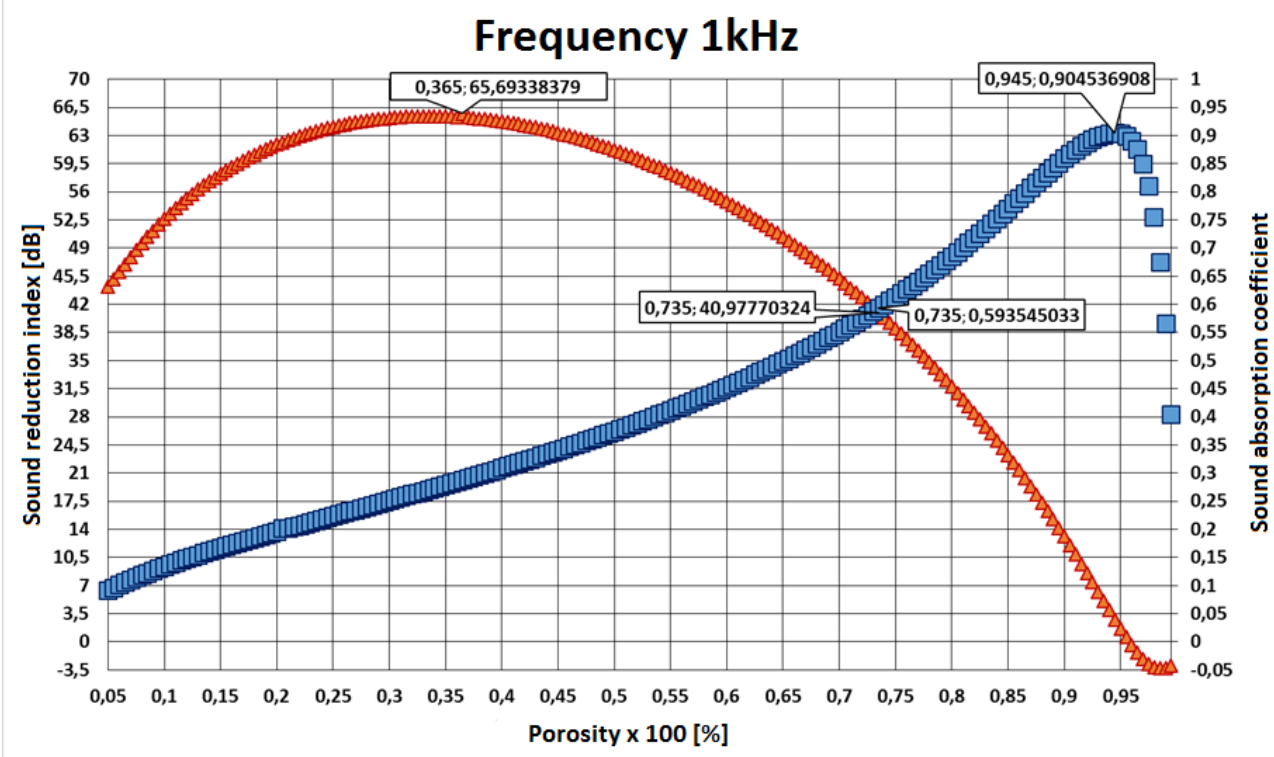

$\Delta$ Sound reduction index $\square$ Sound absorption coefficient

Fig. 3. The characteristics of sound reduction index and sound absorption coefficient depending on the material porosity at $1 \mathrm{kHz}$ frequency [own research].

\section{Frequency $1 \mathrm{kHz}$}

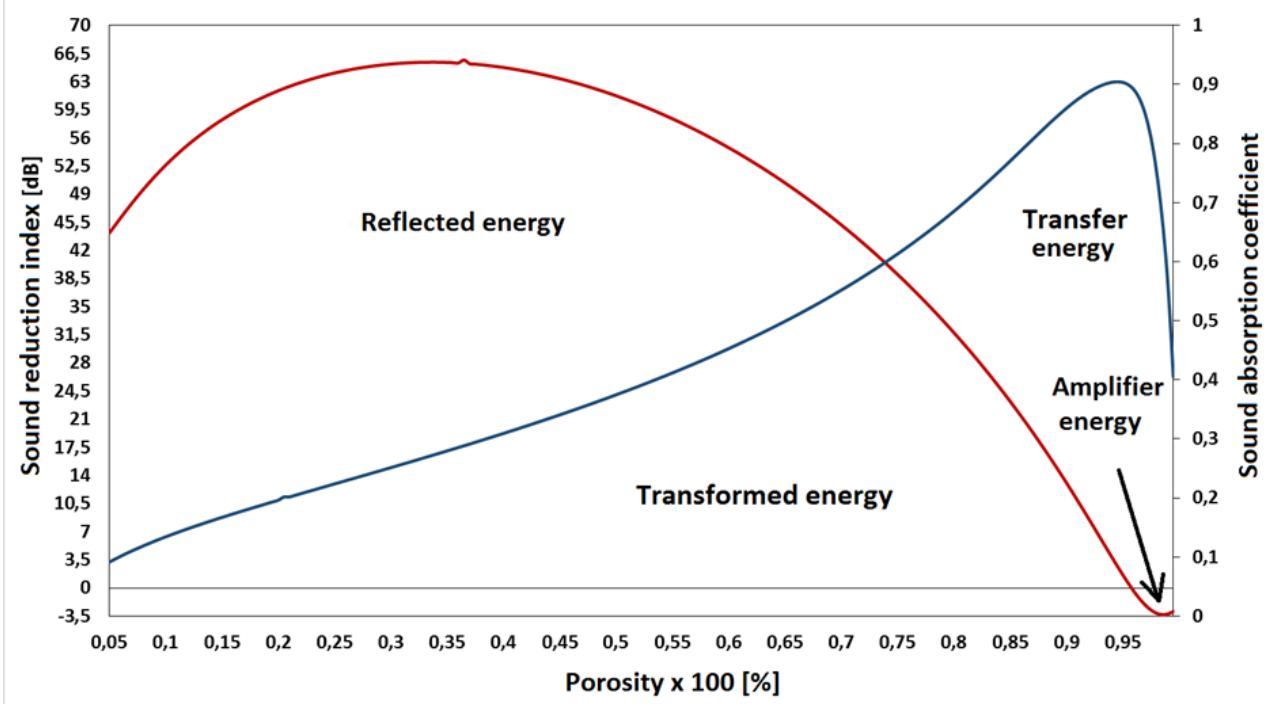

- Sound reduction index $\quad$-Sound absorption coefficient

Fig. 4. Energy balance of acoustic energy transfer through porous filamentary microstructure. [own research].

The mathematical model can create a geometrical model of the filamentary material microstructure, which in principle acts as a breaker of acoustic waves. Effect of material porosity is very important, for that a simple porosity measuring of mineral wool, material STERED ${ }^{\circledR} 200$ and STERED ${ }^{\circledR} 250$ was done, by using direct method porosity measuring. This method is suitable only for very regular shapes of test samples. The measuring 
samples must be completely saturated by liquid (water) under vacuum. The volume of pores was directly determined from difference between dry and saturated sample on the base on the know bulk density of water, which was in the pores of porous material. [2, 3]

Table 1. Studied measure samples of porous material. [own research]

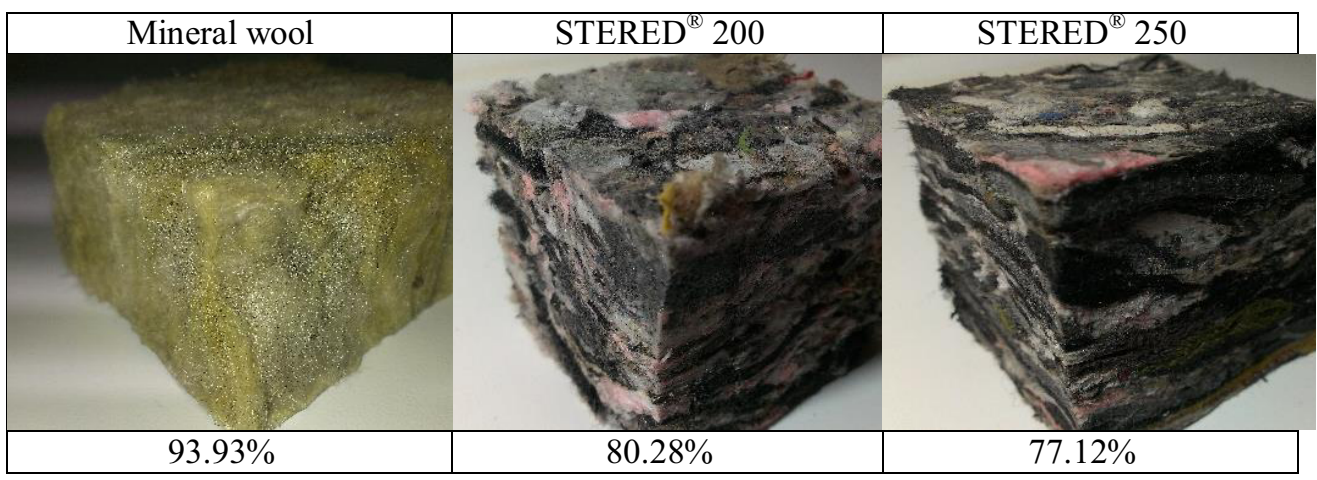

\section{Application of STERED materials on the railway track}

\subsection{Active noise measures on railway track}

Active noise measures on the railway track include mainly: regular maintenance of the railway superstructure, application of modern structures of railway superstructure and types of switches, quality structure of the rail, appropriate structures of bridges, the use of antivibration mats and pads into the structure of railway superstructure and in the last years rail dampers fixed to the rail, too.

The rail damper, thanks to its structural composition, has high absorption properties (Fig. 5a, b), which absorbs the vibrations at the wheel/rail interface, and thus prevents generating noise in rail. In the case of train passing, noise is generated in different frequency spectra in the contact between the wheel and rail. Rail damper works on the absorption of vibration for frequencies with the greatest levels of noise. In case of low and high frequencies that correspond to lower levels of noise, the structure of rail damper is designed to have no effects on the amount of noise generated. On the contrary, in the case of frequencies, which are characteristic for most of the noise generated, rail damper is the most effective. Rail damper that prevents the spread of the vibration wave causes its faster absorption. [4]

Studies conducted by German (DB) and French (SNCF) Railways, at the rail track section with rail dampers installed, showed a reduction in noise up to $6 \mathrm{~dB}$ (A) and vibration up to $9 \mathrm{~dB}$. [5]. The main advantage is that they can be installed even after the installation of the section at critical locations to improve noise parameters after putting construction into operation. There are no restrictions in the railway maintenance, the rail absorber is maintenance-free and does not affect the overall appearance of railway tracks. [6] 

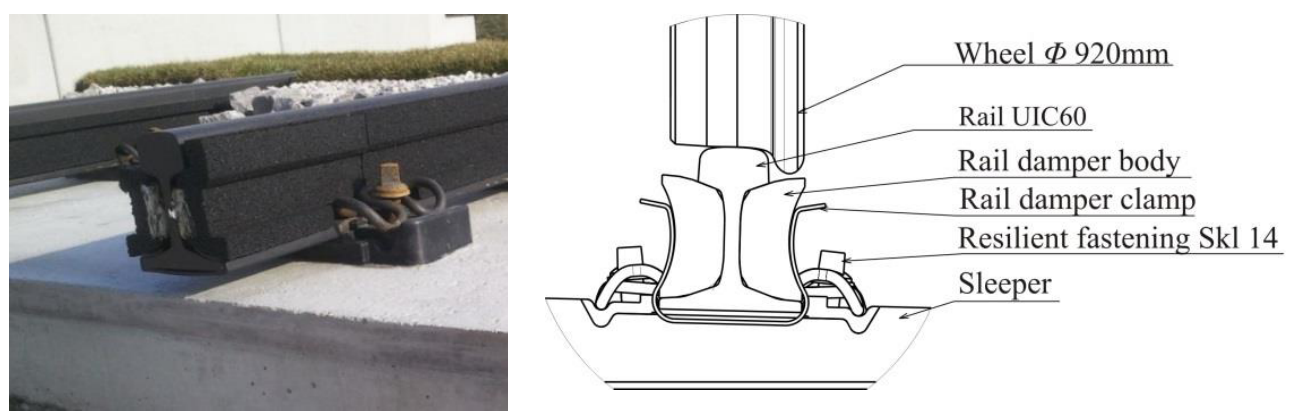

Fig. 5. (a) Rail damper made from STERED [8] ; (b) Rail damper cross-section [own research].

\subsection{Passive noise arrangements in the railway track}

Passive noise arrangements can be implemented directly on the structure of the railway track or railway vehicle. Noise arrangements, which are part of the railway track include Noise enclosure, Noise barrier (Fig. 6 a)), Near track barrier, Low noise barrier (Fig. 6 b)), Track-bed absorption (Fig. 7 a)), Rail track slab (Fig. 7 b)).

Regarding its excellent and extraordinary acoustic parameters, the STERED product offers extensive application in anti-noise measures. High degree of noise absorbing, resistance to climate conditions, low specific mass, enable to choose a system of low antinoise barriers along with comparable acoustic results as standard high anti-noise walls exert.

Low anti-noise barriers can contribute distinctly to higher traffic safety - better visibility, better access of rescue services; they also represent distinct landscape forming character. Other distinct contribution is the better visibility for all traffic participants, in particular as for crossing between different kinds of traffic - railway crossings.

Placing a low anti-noise barrier combined with crash barrier of divided road can be a contribution to reducing the solution costs of anti-noise measures behind contra directional traffic lanes. This fact holds for both roadsides of the communication body. Another advantage of low anti-noise solutions for increasing safety (driver's attention) is removing the driving in tunnel effect because of starting occurrence of long road sectors with antinoise walls up to $4 \mathrm{~m}$ high. STERED ID, insulating plate, provides high factor of absorption even for low frequencies. Frequency characteristics of noise absorption, applied for traffic noise spectrum according to STN EN 1793-3, prove that the material is suitable for the construction of anti-noise barriers as equipment for traffic noise reduction with high degree of absorption (category A4). Certainly, it is necessary not to exceed the limit values specified in the Decree 549/2007 of the Ministry of Health of the Slovak Republic [7]. Application of STERED material increases noise absorption of traditional anti-noise measures, together with extending of absorbing spectrum thanks to its parameters of high absorption starting from $400 \mathrm{~Hz}$ frequency. Examples of STERED solutions are given on following pictures. [8] 


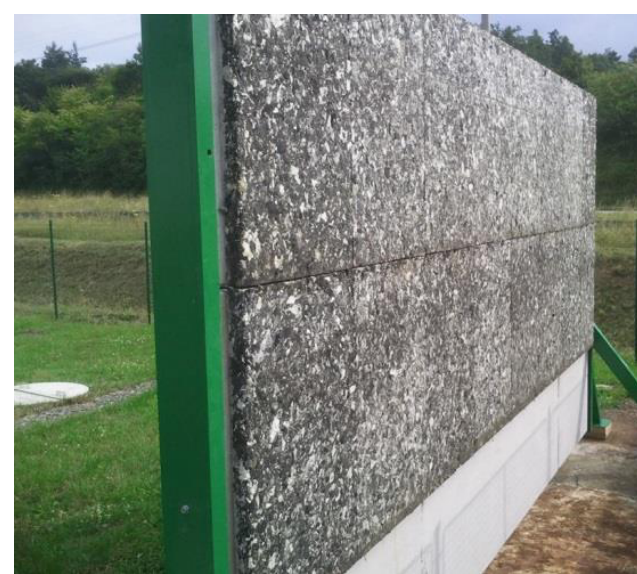

a)

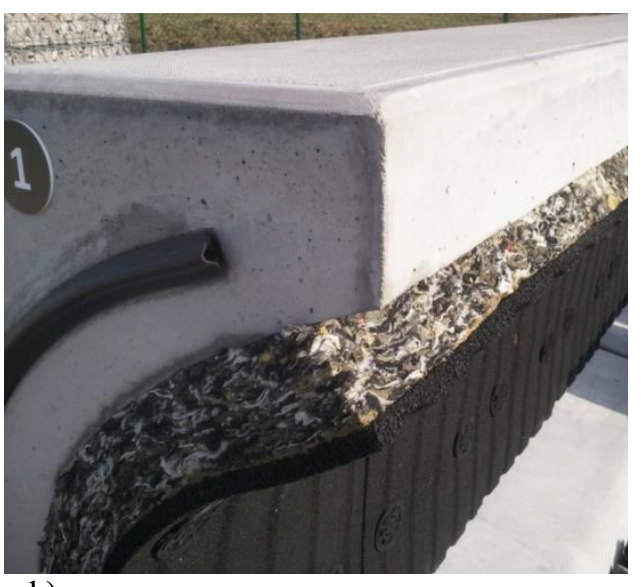

b)

Fig. 6. a) STERED in high acoustics barrier design b) STERED in low acoustics barrier using on the railway [8].

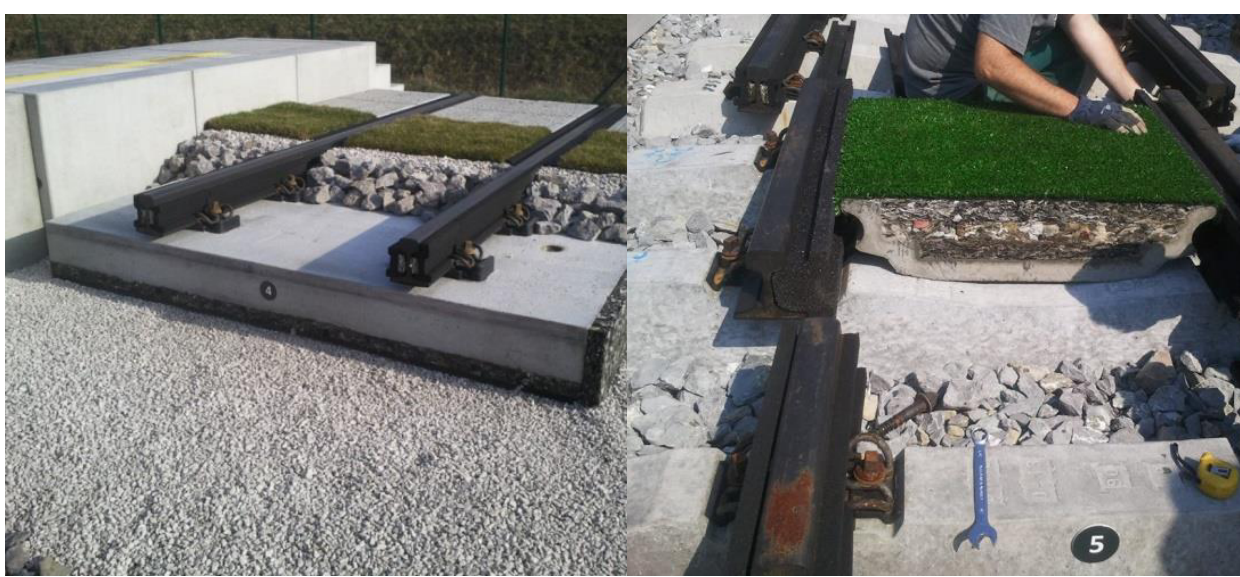

a)

Fig. 7. a) STERED in railway bed design b)

b) STERED in rail track slab [8].

\section{Conclusions}

There are several negative environmental factors of railway transport perceived by public, among which air pollution as consequence of energy consumption, especially for diesel traction, and noise produced by railway are the most significant. Numerous efforts have been done in both areas to minimize the effects. This study deals with possibilities of noise reduction on railway wagons and railway track using new materials with enhance acoustic properties.

Among other benefits of the STERED $\AA$ material, which has been proposed to be used in railway noise reducing systems, is that the material is obtained from recycling of the textile waste used as thermal and acoustic insulators in the automotive industry. The base material consists of synthetic fibres with high resistance against environmental effects. Thus, it can be used even outdoors, and has wide range of applications. 
The main aim of using STERED ${ }^{\circledR}$ material is to provide good sound reduction of acoustics barriers in railway track, rail damper and using in others application of noise reduction on the railway.

In the searching suitable technical solutions and methods of noise reduction, it is important to recognize suitability of using a sound absorption material, or sound reduction material, what depends on actual acoustics situation. By using suitable process of simulation calculation it is relatively easy to diagnose vibro-acoustics paths and sources of acoustics energy. Consequently, it is important to find technical solutions for elimination effect of the vibro-acoustic path. For proper choice of the material it is important to know effect of porosity and to find optimum as a balance between sound reduction and sound absorption that are dependent on the porosity. The effect have been studied in the research and results optimum porosity for both parameters have been revealed.

The paper was created within the framework of project VEGA 1/0766/15 " Research of noise emissions sources in the railway transport and methods of their effective reduction ".

\section{References}

1. Y. Champoux, J.F. Allard, J. Appl. Physics 70, (1991)

2. T. Bourbié, O. Coussy, B. Zinszner, Acoustics of porous media (Institut francais du pétrole publications, Paris, 1987).

3. M. Matka, J. Gołembiewski, Z. Koza, Proc. of the 5th Int. Conf. on Porous Media and its App. in Sci. and Eng. (Engineering Conferences International, Hawaii, 2014).

4. D. Benton, CORUS RAIL, FRANCE SA 5, (2007)

5. S.Lakušić, M. Ahac, Technički vjesnik 19, 429 (2012)

6. A.Pultznerová, L.Ižvolt, Proc. Eng. 91, 274-279 (2014)

7. A. Pultznerová, M. Mečár, Logistyka 4(3), 3188 (2014)

8. Stered in traffic infrastructure Information on http://www.stered.sk/stered-vdopravnej-infrastrukture?lang=en 